\title{
Sustainable processes for pre-treatment of cotton fabric
}

\author{
Rachana S. Harane and Ravindra V. Adivarekar
}

\begin{abstract}
Simple and sustainable reuse and recycle strategies were investigated with the intention of assessing ways to curb water consumption in the textile wet processing. Textile pre-treatment involves desizing, scouring and bleaching processes. Each process requires a plethora of chemicals along with water, out of which the unexhausted chemicals are drained in the effluent stream. Conventionally, $7.3 \%$ alkali and $6.9 \%$ hydrogen peroxide are utilised in the scouring and bleaching process. Attempts were made to reutilise the unexhausted $92.7 \%$ alkali and $93.1 \%$ hydrogen peroxide from the scouring and bleaching process. After recycling the scouring and bleaching process bath three times, effluent still contained $55 \%$ alkali and $67.5 \%$ hydrogen peroxide which was reused to desize a new grey fabric. The fabric properties like Tegewa rating, absorbency and whiteness were found to be better than the conventional enzyme desized fabric. The desized fabrics were then subjected to dyeing using reactive dyes Yellow HE6G and Navy Blue HER, where analogous dyeing and fastness properties were obtained when compared with fresh water samples. Economical feasibility has been calculated considering a production of 1 ton of fabric/day. It was observed that $83 \%$ water and $74 \%$ energy were conserved per ton of processed fabric which contributes to a saving of around 1 lac INR/ton.
\end{abstract}

Keywords: Textile industry, Wastewater, Recycling, Reuse, Pre-treatments, Cotton woven fabric, Reactive dyeing

\section{Background}

The emergence of industrialisation and urbanisation aggravates the situation of increasing demand for water. According to a survey conducted by FICCI Water Mission, demand of water for the industrial sector is likely to witness a rise up to 8.5 and $10.1 \%$ of the total freshwater withdrawal in 2025 and 2050, respectively (FICCI 2011). Currently, the Indian textile industry consumes $200-300 \mathrm{~m}^{3}$ of water per ton of the processed textiles also generating a huge quantum of wastewater (Dasgupta et al. 2015; Ranganathan et al. 2007). The wastewater that is discharged contains appreciable quantities of organic and inorganic chemicals (dyes, acids, alkalis, lubricants, surfactants, auxiliaries, oligomers, etc.) which have to be treated to comply with the norm set by the pollution control board and other environmental organisations. Due to an increase in demand of the textiles and the stringent rules, the waste treatment plant has to be expanded or additional treatment facilities are

\footnotetext{
* Correspondence: rv.adivarekar@ictmumbai.edu.in

Department of Fibres and textile Processing Technology, Institute of Chemical Technology (ICT), Matunga, Mumbai 400019, India
}

required. The textile companies drain their effluent to the common effluent treatment plants (CETPs), where the CETPs charge them on the basis of the quality and quantity of the wastewater. Thus, by stream identification and segregation, one can study the potential of wastewater streams for its possible recycle and reuse. This will drastically reduce the quantity of wastewater going into the CETPs.

Many different strategies are employed for wastewater treatment such as use of high-energy gamma radiation to degrade the combined textile wastewater for its reuse in wet processing (Rahman Bhuiyan et al. 2016). Membrane systems is the latest methodology for the treatment-recycling scheme to recover the chemicals and water (Fersi et al. 2005; ElDefrawy and Shaalan 2007; Ranganathan et al. 2007; Lu et al. 2010). Dasgupta et al. 2015 have considered both biological systems and membrane technology for wastewater reclamation. Erdumlu et al. (2012) have mentioned that the effluent obtained from different finishing processes may be reused by partial purification. They have introduced a method of reusing water just after basic treatments like
照 Springer

(c) 2016 Harane and Adivarekar. Open Access This article is distributed under the terms of the Creative Commons Attribution 4.0 International License (http://creativecommons.org/licenses/by/4.0/), which permits unrestricted use, distribution, and reproduction in any medium, provided you give appropriate credit to the original author(s) and the source, provide a link to the Creative Commons license, and indicate if changes were made. 
filtering, airing, $\mathrm{pH}$ regulating and ion exchange. Another simple process was put forward by Schoeberl et al. (2005), where only the washing effluents from a textile finishing company was treated by means of ultrafiltration. Reuse of bleach rinse for after-scour rinsing operation can be possible as mentioned by Skelly in his Book titled 'Water recycling in textile wet processing' (Skelly 2003).

The concept of segregation of wastewater was followed by Shaid et al. (2013) where scouring and bleaching rinses have shown bright prospect of reusing. Amongst many rinses tested, the 'before dyeing rinse' of knitted cotton fabric was found to be acceptable and safe to reuse for scouring-bleaching of the same fabric with addition of the same amount of chemicals.

It was noticed that although attempts have been made to recycle and reuse the wastewater, they involved partial or complete treatment before its recycle and reuse. Literature is void of studies wherein optimal use of process chemicals before draining into the wastewater stream was considered.

The focus of this research is on recycling and reusing water and chemicals in the textile pre-treatment process without prior treatment. Before describing the research objective, the concepts of reusing and recycling are defined which are often misunderstood. The US Environmental Protection Agency (2004) have defined the two concepts aptly, reuse means utilisation of previously used wastewater for another process or purpose whereas recycle can be defined as reuse of same wastewater one or more times for the same process or

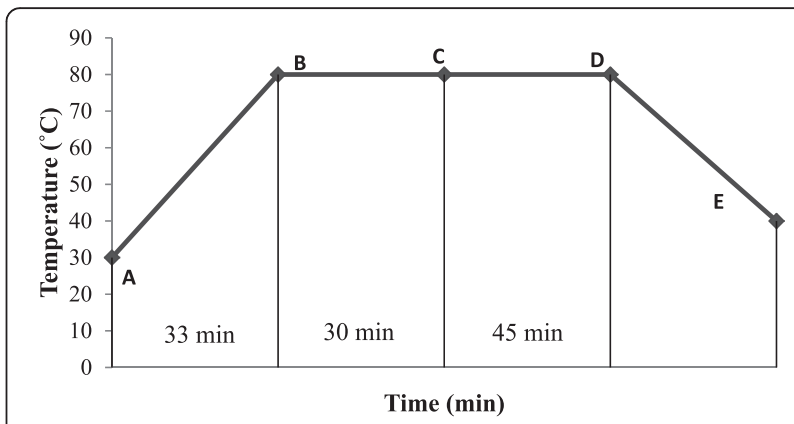

Fig. 2 Conventional reactive dyeing graph. The conventional reactive $\mathrm{HE}$ dyeing process is explained through time vs temperature graph. Where; $\mathrm{A}$ : Addition of fabric, required amount of dye and salt $\left(40 \mathrm{~g} \mathrm{~L}^{-1}\right)$ at room temperature, $\mathrm{A}-\mathrm{B}$ : Raise temperature upto $80^{\circ} \mathrm{C}$ with heating rate $1.5^{\circ} \mathrm{C} / \mathrm{min}, \mathrm{B}-\mathrm{C}$ : Run bath for $30 \mathrm{~min}$ at $80^{\circ} \mathrm{C}, \mathrm{C}$ : Addition of sodium carbonate $\left(20 \mathrm{~g} \mathrm{~L}^{-1}\right), \mathrm{C}-\mathrm{D}$ : Dyeing for $45 \mathrm{~min}$, E: Washing and rinsing.

purpose. The conventional three step pre-treatment process consists of desizing, scouring and bleaching. Desizing of a grey fabric removes previously added size or starchy material which can be done by using water (rot steeping), acid, enzyme, oxidation chemicals and alkali. Scouring uses alkali to remove oils, fats and waxes to improve the absorbency whereas bleaching uses oxidising agents to improve the whiteness of the fabric. In a conventional process, scouring and bleaching is done once which results in under utilisation of alkali and hydrogen peroxide. In the proposed process, wastewater from scouring and bleaching has been recycled three times for optimal utilisation of chemicals and water; the fabric properties were compared with

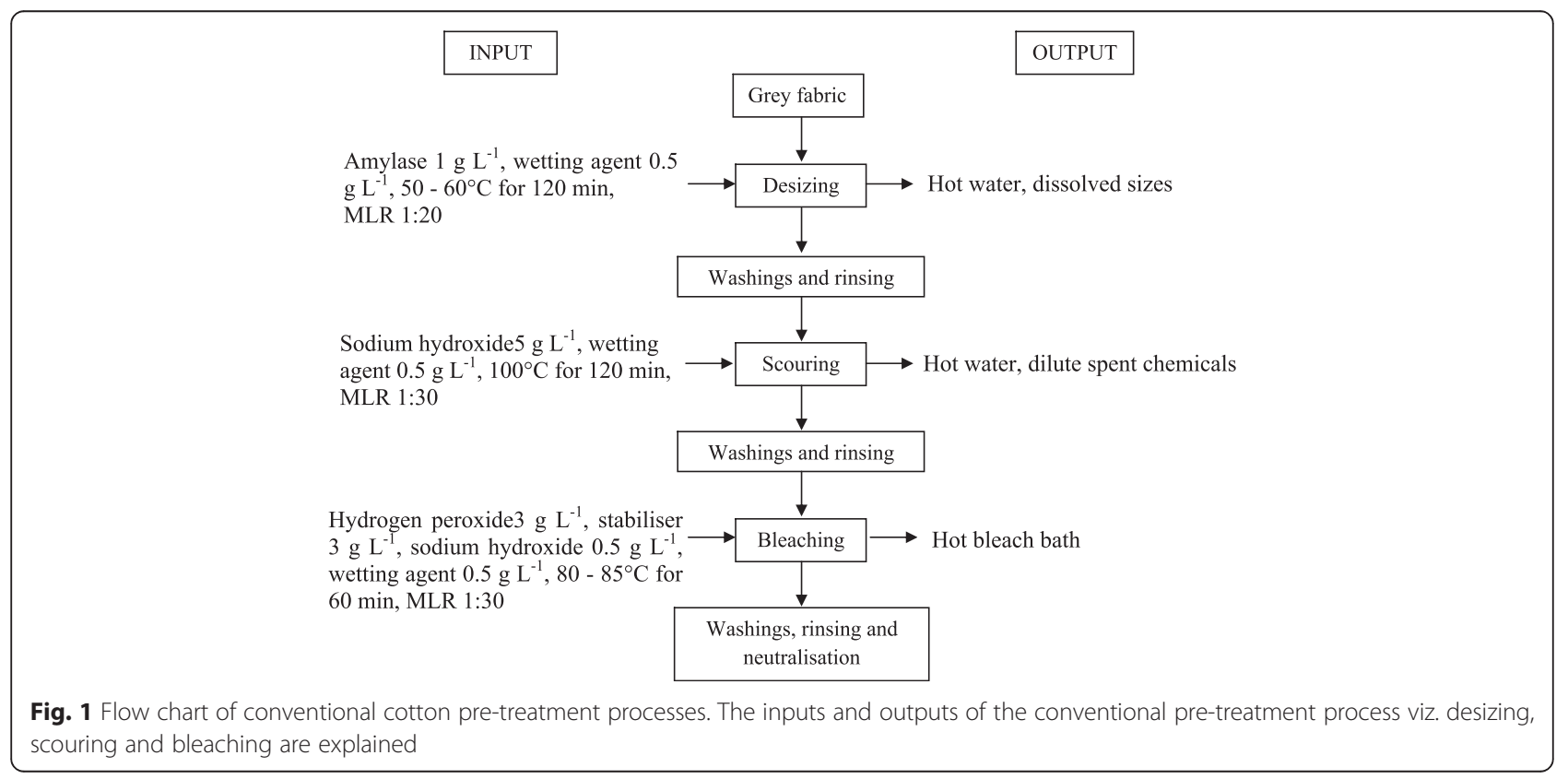




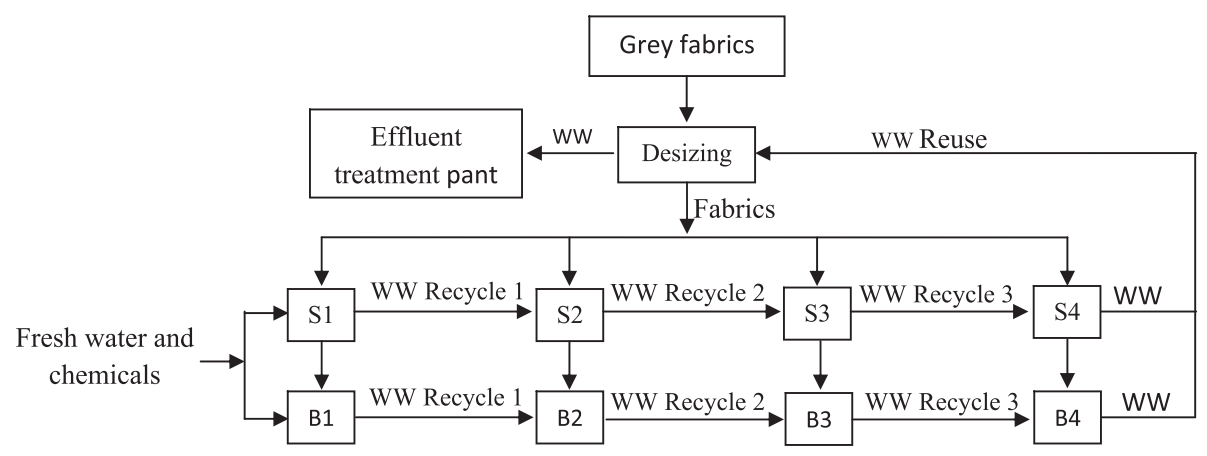

Fig. 3 Schematic flow diagram of the proposed recycle and reuse process. This showcases the actual idea of water recycling in scouring and bleaching baths (three times) without replenishment of water or chemicals. Further mixing the wastewater after third recycled scouring and bleaching baths in 50:50, 70:30 and 30:70 ratios, respectively, and desize a new grey fabric using it. At the last, dyeing of all fabrics is carried. Where; WW: wastewater, S1, S2, S3 and S4: Scouring processes 1,2,3,4 respectively, B1, B2, B3 and B4: Bleaching processes 1,2,3,4 respectively.

the conventionally processed fabrics. After recycling the process water three times, the baths still contain alkali and oxidising agents. Hypothesis has been made to reuse the scouring and bleaching process water in the proportions of 50:50, 70:30 and 30:70 for desizing a grey fabric. Fabric properties were compared with conventional enzymatic desizing.

To further confirm the quality of the processed fabric, dyeing has been done using reactive dyes. Technical feasibility of the process was evaluated on the basis of Tegewa rating, absorbency, whiteness index and dyeing and fastness properties. Economical feasibility has also been studied.

\section{Methods}

\section{Materials}

A $100 \%$ grey cotton plain woven fabric obtained from Tata mills, Mumbai, was used throughout the experiment. The fabric had a yarn count of 40 s and a gram per square metre (GSM) of 112. The chemicals, wetting agents, sodium hydroxide, hydrogen peroxide, peroxide stabiliser, glacial acetic acid, sulphuric acid, potassium iodide, iodine, Glauber's salt and sodium carbonate were obtained from S.D. Fine chemicals and were of AR grade. Reactive dyes, Yellow HE6G and Navy Blue HER were obtained from Colorband India Pvt. Ltd and were used without any further purification.

\section{Conventional method}

Untreated fabric, also known as grey fabric, was desized, scoured and bleached in separate baths as per the procedure given in literature (Koushik and Josico 2003; Shore 1995; Tomasino 1992). All the processes were carried out in the lab scale Rota dyer (Rossari Labtech, Mumbai, having a capacity of $1800 \mathrm{ml}, 18$ pots each with a capacity of $100 \mathrm{ml}$ ). The flow chart of the same can be seen from Fig. 1.

Pre-treatment of fabric was followed by dyeing. For this study, reactive HE dyes were used. In order to dye a cotton fabric using reactive HE dye with $1 \%$ shade, $20 \mathrm{~g} \mathrm{l}^{-1}$ sodium carbonate and $40 \mathrm{~g}^{-1}$ Glauber's salt are required. The time vs temperature graph of dyeing is shown below in Fig. 2.

\section{The proposed recycle and reuse method}

Scouring followed by bleaching of a desized fabric was carried out using the conventional recipes. The process bath of scouring and bleaching still containing unexhausted chemicals was recycled as it is without addition of any extra chemicals three times. The final, i.e. the third bath of both the scouring and bleaching processes were then mixed in 50:50, 70:30 and 30:70 proportions, respectively, and were reused to desize a new grey fabric. The fabrics thus desized with the recycled water were subjected to reactive dyeing. A flow diagram of the same can be seen from Fig. 3.

Table 1 Properties of scoured fabrics

\begin{tabular}{lllllll}
\hline Sr. no. & Fabric samples & $L^{*}$ & $a^{*}$ & $b^{*}$ & Tegewa rating & Absorbency $(s)$ \\
\hline 1. & Scoured fabric & 88.36 & -0.12 & 6.49 & 6 & $<3$ \\
2. & Scoured fabric (1 ${ }^{\text {st }}$ recycle) & 88.22 & -0.38 & 7.31 & 6 & $<3$ \\
3. & Scoured fabric (2 ${ }^{\text {nd }}$ recycle) & 89.08 & -0.47 & 7.61 & 6 & $<3$ \\
4. & Scoured fabric (3 ${ }^{\text {rd }}$ recycle) & 88.94 & -0.44 & 7.83 & 6 & $<3$ \\
\hline
\end{tabular}


Table 2 Measurement of alkalinity in scouring baths

\begin{tabular}{|c|c|c|c|c|}
\hline Sr. no. & Samples & & Alkalinity $\left(\mathrm{mg} \mathrm{CaCO}_{3} / \mathrm{l}\right)$ & Alkali consumption (\%) \\
\hline \multirow[t]{2}{*}{1.} & Scouring & Before treatment & 6000 & 8.3 \\
\hline & & After treatment & 5500 & \\
\hline 2. & $1^{\text {st }}$ recycle & & 4750 & 21 \\
\hline 3. & $2^{\text {nd }}$ recycle & & 4000 & 33 \\
\hline 4. & $3^{\text {rd }}$ recycle & & 3300 & 45 \\
\hline
\end{tabular}

\section{Testing and analysis}

\section{Testing of desized fabric}

Iodine drop test (Tegewa test) is employed to check the desizing efficiency. The underlying principle for the same is the violet colouration of starch with iodine. Hence, the presence of starch remaining on fabric can be deciphered. A small sample of desized fabric was cut and immersed in a beaker containing a solution of potassium iodide and iodine for $1 \mathrm{~min}$. The sample was then rinsed thoroughly under tap water, dabbed with filter paper and immediately compared with the Tegewa scale or Violet scale having a 1-9 rating. A rating of 1 denotes almost no removal of size and a rating of 9 indicates complete removal of size from the fabric. The commercially acceptable rating is 6-7 (Wurster et al. 1987).

\section{Testing of scoured fabric}

Absorbency of a fabric was performed by using AATCC Test Method 79-2000, where a drop of water is allowed to fall from a fixed height onto the taut surface of a test specimen. The time required for the reflection of the water drop to disappear is measured and recorded as wetting time. Five seconds or less is generally considered to represent adequate absorbency (Chehna et al. 2007).

\section{Testing of bleached fabric}

The bleached fabrics were evaluated for whiteness index using a computer colour matching system (SpectraScan 5100+) supplied by Premier Colorscan Instruments Pvt. Ltd. Evaluation for whiteness index was carried out using AATCC Test Method 110-2005. An average of two readings taken at two different positions of samples was used to calculate the indices (Chehna et al. 2007).

\section{Presence of alkali in the scouring bath}

In this test, the accurately measured volume of specimen was titrated against standard solution of sulfuric acid using a phenolphthalein indicator. The alkalinity measured is in terms of $\mathrm{CaCO}_{3}$ (mg/l) (American Public Health Associations et al. 1999).

$$
\text { Alkalinity, mg } \mathrm{CaCO}_{3} / \mathrm{l}=\frac{(A)(N)(50,000)}{\mathrm{ml} \mathrm{sample}}
$$

where

$A$ : millilitre of the standard acid used,

$N$ : normality of the standard acid.

\section{Presence of hydrogen peroxide in the bleaching bath}

AATCC Test Method 102-2002 was used to determine hydrogen peroxide in the bleach bath. A specimen is acidified with sulphuric acid and titrated with standardised potassium permanganate solution. The concentration of hydrogen peroxide is calculated using the volume and normality of the permanganate solution used (Chehna et al. 2007).

$$
\% \mathrm{H}_{2} \mathrm{O}_{2}=\frac{(V \mathrm{t}-V \mathrm{~b})(N \mathrm{t})(0.017)(100)}{W \mathrm{~s}}
$$

where

$V \mathrm{t}$ : volume of titrant in millilitres,

$\mathrm{bb}$ : volume of titrant in millilitres for blank sample,

$N$ t: normality of the titrant solution,

Ws: specimen mass, in grams.

\section{Presence of alkali in the bleach bath containing peroxide}

This test is carried as per AATCC Test Method 98-2002. A weighed specimen of the bleach bath is titrated with a standardised solution of sulfuric acid using Phenol Red

\begin{tabular}{|c|c|c|c|c|c|c|c|c|c|}
\hline Sr. no. & Fabric samples & $L^{*}$ & $a^{*}$ & $b^{*}$ & Tegewa rating & Absorbency (s) & WI & $\mathrm{Yl}$ & $\mathrm{Bl}$ \\
\hline 1. & Bleached fabric & 90.84 & -0.36 & 4.37 & 6 & $<3$ & 58.4 & 7.8 & 73.9 \\
\hline 2. & Bleached fabric ( $1^{\text {st }}$ recycle) & 89.77 & -0.39 & 4.77 & 6 & $<3$ & 51.7 & 8.7 & 69.2 \\
\hline 3. & Bleached fabric (2 $2^{\text {nd }}$ recycle) & 89.51 & -0.57 & 5.26 & 6 & $<3$ & 51.2 & 9.3 & 70.2 \\
\hline 4. & Bleached fabric ( $3^{\text {rd }}$ recycle) & 89.28 & -0.71 & 5.78 & 6 & $<3$ & 47.9 & 10.3 & 69.2 \\
\hline
\end{tabular}

Table 3 Properties of bleached fabrics

WI whiteness index, $Y$ I yellowness index, $B I$ brightness index 
Table 4 Measurement of peroxide content and alkalinity in bleaching baths

\begin{tabular}{|c|c|c|c|c|c|c|}
\hline Sr. no. & Samples & & Peroxide content (mg/l) & Peroxide consumption (\%) & Alkalinity (mg $\left.\mathrm{CaCO}_{3} / \mathrm{l}\right)$ & Alkali consumption (\%) \\
\hline \multirow[t]{2}{*}{1.} & Bleaching & Before treatment & 430 & 6.9 & 200 & 30 \\
\hline & & After treatment & 400 & & 140 & \\
\hline 2. & $1^{\text {st }}$ recycle & & 370 & 13.9 & 120 & 40 \\
\hline 3. & $2^{\text {nd }}$ recycle & & 330 & 23.2 & 80 & 60 \\
\hline 4. & $3^{\text {rd }}$ recycle & & 290 & 32.5 & 80 & 60 \\
\hline
\end{tabular}

indicator or to the $\mathrm{pH}$ range $6.8-8.4$ on a $\mathrm{pH}$ metre. The total alkali, expressed as $\% \mathrm{NaOH}$, is calculated based on the weight of the bath (Chehna et al. 2007).

$$
\% \text { Total alkali, as } \mathrm{NaOH}=\frac{(\mathrm{ml})(N)(0.040)(100)}{W}
$$

where

$\mathrm{ml}$ : the number of millilitres of the sulphuric acid solution required,

$N$ : the normality of the sulphuric acid solution, 0.040: the milliequivalent weight of sodium hydroxide, $W$ : mass of the specimen.

\section{Colour depth (in terms of $K / S$ value and colour strength)} and tone of the colour (in terms of $L^{*}, a^{*}$ and $b^{*}$ values) Dyed samples were evaluated for the depth of the colour by determining $K / S$ values as well as colour strength using a computer colour matching system (SpectraScan 5100+) supplied by Premier Colorscan Instruments Pvt. Ltd. An average of two readings was taken at two different positions of samples and was used to calculate the reflectance values and KubelkaMunk $K / S$ function which is given by

$$
\frac{K}{S}=\frac{(1-R)^{2}}{2 R}
$$

where

$R$ : reflectance at complete opacity,

$K$ : absorption coefficient,

$S$ : scattering coefficient.

The dyed samples were also evaluated in terms of $L^{*}$, $a^{*}, b^{*}, C, h$ and $\mathrm{dE}$. The colour difference (dE) can be visualised as the distance between the standard or reference and the sample points plotted in the $L^{*} a^{*} b^{*}$ colour space. $L^{*}$ values have a range of $0-100,100$ indicates lightness or white and 0 indicates darkness or black. Negative values of ' $a$ '”' indicate green while positive values indicate red, whereas negative values of ' $b$ "' indicate blue and positive values indicate yellow. The $L^{*} a^{*}$ $b^{*}$ system adopted from the CIE in 1976 is the most widely used system today.

$$
\mathrm{dE}=\sqrt{\left(D L^{2}+D a^{2}+D b^{2}\right)}
$$

where

$D L: L$ (sample) $-L$ (standard),

$D a: a$ (sample) $-a$ (standard),

$D b: b$ (sample) $-b$ (standard).

From the CIELAB coordinates, one can compute $C$ (chroma) and $h$ (hue). The chroma or saturation $(C)$ is the distance between achromatic point and colour and is calculated from ' $a$ "'and ' $b$ "' using the following equation:

$$
C=\sqrt{\left(a^{* 2}+b^{* 2}\right)}
$$

The point $a=0$ and $b=0$ lies at the centre of the chromaticity diagram. The lower is the value of ' $a$ "s' and ' $b$ "', the higher is the achromaticity and the lower is the purity. On the other hand, the higher the values of ' $a$ "' and ' $b$ "' (ignore the negative signs), the purer or more saturated or brighter is the colour.

$$
h=\tan ^{-1} \frac{b^{*}}{a^{*}}
$$

Positive values of chroma (or saturation) indicate more saturated colour (i.e. brighter) and negative values indi-

\begin{tabular}{|c|c|c|c|c|c|c|c|c|c|}
\hline Sr. no. & Fabric samples & $L^{*}$ & $a^{*}$ & $b^{*}$ & Tegewa rating & Absorbency (s) & WI & YI & $\mathrm{Bl}$ \\
\hline 1. & Enzyme desized fabric & 84.33 & 0.47 & 11.47 & $5-6$ & $120-160$ & 14.7 & 21.9 & 58.5 \\
\hline 2. & Fabric treated with three times recycled S:B 50:50 & 89.17 & -0.76 & 8.35 & $5-6$ & $10-15$ & 35.7 & 14.8 & 66.6 \\
\hline 3. & Fabric treated with three times recycled S:B 70:30 & 88.62 & -0.47 & 9.63 & $5-6$ & $8-10$ & 28.0 & 17.5 & 64.1 \\
\hline 4. & Fabric treated with three times recycled S:B $30: 70$ & 89.97 & -0.96 & 7.71 & $5-6$ & $20-25$ & 40.4 & 13.1 & 68.8 \\
\hline
\end{tabular}
cate less saturated colour (i.e. duller). Hue is an angle measured in degree and can also be termed as purity of colour (Sule 1997).

Table 5 Properties of fabric desized using recycled process water

$S$ scouring process water (recycled three times), $B$ bleaching process water (recycled three times) 
Table 6 Dyeing properties of fabric dyed using Yellow HE6G

\begin{tabular}{lllllllll}
\hline Sr. no. & Fabric samples & $L^{*}$ & $a^{*}$ & $b^{*}$ & $C$ & $h$ & $\mathrm{dE}$ & \multicolumn{2}{c}{ K/S } \\
\hline 1 & STD RFD sample & 84.98 & -14.13 & 47.63 & 49.69 & 106.55 & - & 2.33 \\
2 & Treated in S:B 50:50 & 85.6 & -13.69 & 48.18 & 50.06 & 105.89 & 0.98 & 2.83 \\
3 & Treated in S:B 70:30 & 85.35 & -12.80 & 48.11 & 49.79 & 104.92 & 1.46 & 2.65 \\
4 & Treated in S:B 30:70 & 86.00 & -13.80 & 49.02 & 50.93 & 105.75 & 1.75 & 2.74 \\
\hline
\end{tabular}

STD RFD standard ready for dyeing fabric

\section{Colour fastness evaluation of dyed samples}

Colour fastness to washing was performed in a Laundrometer by using ISO 105-C03 (1989). Colour fastness to rubbing was done on a Crockmeter by using ISO 105 X12 (2001). Light fastness of dyed samples was evaluated on a Q-sun light fastness tester by following AATCC 16E method which is similar to ISO 105-A02 (2013).

\section{Results and discussion}

With the aim of utilising alkali, scouring process water was recycled three times and the properties of fabric are tabulated in Table 1, whereas, the utilisation of alkali after every recycle is reported in Table 2.

When the process water of scouring was recycled, the Tegewa rating and absorbency of the fabrics were in line with the one scoured with fresh water.

From Table 2, it can be observed that conventionally $8.3 \%$ alkali was utilised, whereas in the proposed recycle process it is $45 \%$. Thirty-six percent excess of alkali has been used which saves the chemicals and reduces the cost of chemicals.

It is seen from Table 3 that the Tegewa rating and absorbency of recycled fabrics are similar to those of the conventional bleached fabrics. There was only a slight reduction in the whiteness index by recycling bleached water. The consumption of hydrogen peroxide and alkali after each recycle is seen from Table 4.

Bleaching of a scoured fabric with fresh water utilises $6.9 \%$ hydrogen peroxide and $30 \%$ alkali. Remaining $93.1 \%$ hydrogen peroxide and $70 \%$ alkali is drained into the wastewater. It has also been reported by Cardamone and Marmer (1995) that only $15-25 \%$ of the peroxide in the bleach bath is actually consumed during bleaching, draining remaining into the effluent. When trials were taken to recycle the wastewater without treatment three times, the hydrogen peroxide utilisation and alkali utilisation increased up to 32 and $60 \%$, respectively.

\section{Reuse of scouring and bleaching process water for desizing}

After recycling the scouring and bleaching process water three times, the baths still contain $55 \%$ alkali and $67.5 \%$ hydrogen peroxide (Tables 2 and 4). Desizing of a grey fabric can also be done by using alkali and oxidising agents. Attempts have been made to reuse alkali and hydrogen peroxide that remained in the scouring and bleaching process to desize a new grey fabric. Water from both the processes was mixed in various proportions (50:50, 70:30 and 30:70) in order to find out an optimum ratio in which their combined effect will enhance the final fabric properties. The properties of fabrics were then compared with the conventional enzymatic desized fabric (Table 5).

From Table 5, it was observed that there is no change in the Tegewa rating, whereas there is an increase in the rate of absorbency by 10 folds and increase in whiteness index by 2.7 times. The reason behind the enhancement in fabric properties might be the presence of alkali and hydrogen peroxide in the scouring and bleaching process water which helps in removing the oils, fats, waxes and the natural coloured impurities during the desizing process also elevating the absorbency and whiteness index of a grey fabric. From the above observations, it has been seen that when the ratio of scouring and bleaching process water changes, the properties of fabric changes. When the amount of scouring process water is more, good absorbency is obtained, whereas if the quantity of bleaching process water is more, the fabric has good whiteness index.

Table 7 Dyeing properties of fabric dyed using Navy Blue HER

\begin{tabular}{lllllllll}
\hline Sr. no. & Fabric samples & $L^{*}$ & $a^{*}$ & $b^{*}$ & $C$ & $h$ & $\mathrm{dE}$ & K/S \\
\hline 1 & STD RFD sample & 45.02 & -4.94 & -18.78 & 19.42 & 255.22 & - & 4.40 \\
2 & Treated in S:B 50:50 & 45.16 & -5.17 & -18.80 & 19.49 & 254.59 & 0.26 & 4.88 \\
3 & Treated in S:B 70:30 & 44.99 & -5.03 & -18.55 & 19.22 & 254.78 & 0.26 & 4.81 \\
4 & Treated in S:B 30:70 & 45.26 & -5.22 & -18.99 & 19.70 & 254.50 & 0.44 & 5.18 \\
\hline
\end{tabular}




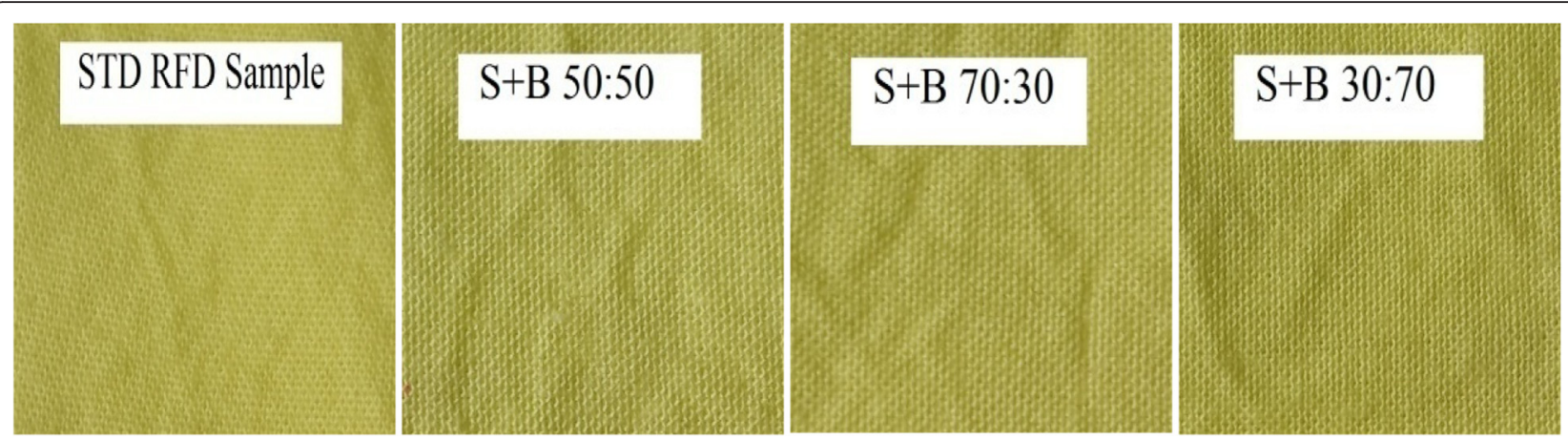

Fig. 4 Samples dyed using Yellow HE6G. First sample is a standard ready for dyeing (RFD) fabric dyed with Yellow HE6G; second, third and fourth dyed ones are grey fabrics desized using scouring to bleaching wastewater in 50:50, 70:30 and 30:70 ratios, respectively

\section{Dyeing of the desized fabrics}

The samples desized with reused process water were then dyed with reactive dyes viz. Yellow HE6G and Navy Blue HER to scrutinise the dyeing performance. The properties of dyed fabrics are given in Tables 6 and 7.

From Tables 6 and 7, it was found that the dyed fabric which was treated with 30:70 ratio of scouring to bleaching process water was brighter than the ready for dyeing (RFD) dyed fabric, which can be confirmed from higher $L^{*}$ values. The $K / S$ value of the dyed fabric is directly proportional to the amount of dye present in the fabric. The fabric treated using the scouring to bleaching process water with both the dyes has shown increased dye uptake which can be seen from higher $K / S$ values than the RFD dyed fabric. The colour difference values $(\mathrm{dE})$ of less than 1 show almost no colour difference when compared with the standard (STD) fabric. In the case of yellow shade, the $\mathrm{dE}$ values between the STD RFD and the scouring to bleaching 50:50 sample (less than 1) indicate acceptable performance in dyeing. In case of blue shade, the $\mathrm{dE}$ values of all the reuse water samples are less than 1 , indicating that all the reused samples are acceptable against the STD dyed fabric. The dyed samples can be seen from Figs. 4 and 5 .

Tables 8 and 9 show the comparison of fastness properties viz. colour, rubbing and light of fresh water and reused water dyed samples.

The reuse process water samples dyed using both the dyes exhibited good fastness to washing, rubbing and light, similar to the standard fabric. This indicates that even when we reuse process water for treating a fresh fabric and subjected to dyeing, the dyeing properties and fastness properties remain in line with the conventional one.

\section{Economical feasibility study}

Two conditions needed to be satisfied by any new process or technology before their implementations in an industry are (1) technical feasibility and (2) economical feasibility.

Technical feasibility has been discussed in the previous sections, and it has been thus proved that recycling and reusing process water decreases not only the water consumption but also the chemical consumption reducing the process cost.

In this section, attempts were made to estimate the water and energy consumption for the conventional as

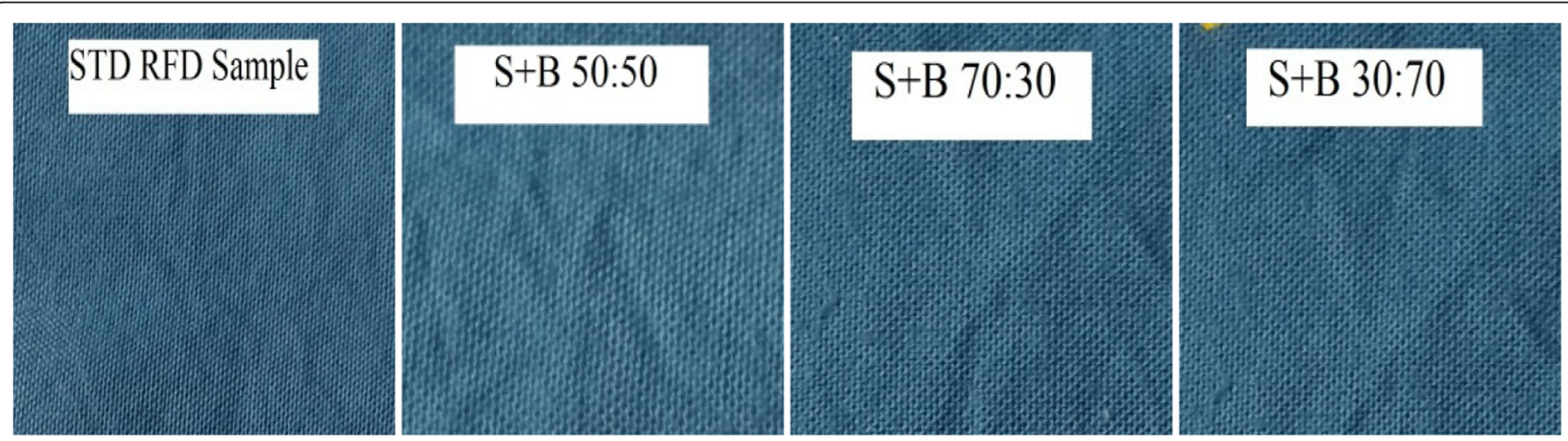

Fig. 5 Samples dyed using Navy Blue HER. First sample is a standard ready for dyeing (RFD) fabric dyed with Navy Blue HER, second, third and fourth dyed ones are grey fabrics desized using scouring to bleaching wastewater in 50:50, 70:30 and 30:70 ratios, respectively 
Table 8 Fastness properties of samples dyed with Yellow HE6G

\begin{tabular}{|c|c|c|c|c|c|c|c|}
\hline \multirow[t]{2}{*}{ Sr. no. } & \multirow{2}{*}{$\begin{array}{l}\text { Dyed fabric } \\
\text { samples }\end{array}$} & \multicolumn{3}{|c|}{ Washing fastness } & \multicolumn{2}{|c|}{ Rubbing fastness } & \multirow{2}{*}{$\begin{array}{l}\text { Light } \\
\text { fastness }\end{array}$} \\
\hline & & $\overline{C C}$ & SC & SW & Dry & Wet & \\
\hline 1. & STD RFD sample & $4-5$ & 4 & 4 & $4-5$ & $4-5$ & 6 \\
\hline 2. & S:B 50:50 & $4-5$ & 4 & 4 & $4-5$ & $4-5$ & 6 \\
\hline 3. & $S: B$ 70:30 & $4-5$ & 4 & 4 & $4-5$ & $4-5$ & 6 \\
\hline 4. & $S: B$ 30:70 & $4-5$ & 4 & 4 & $4-5$ & $4-5$ & 6 \\
\hline
\end{tabular}

well as the proposed recycle and reuse method. The cost has been calculated on the basis of production of 1 ton fabric/day.

Water consumption was calculated on the basis of material to liquor ratio (as shown in Tables 10 and 11), whereas the heat energy calculations were done by using the following formula:

$$
\text { Heat required }=\mathrm{m}(\mathrm{kg} / \mathrm{s}) \times C \mathrm{p}\left(\frac{\mathrm{J}}{\mathrm{kg}^{\circ} \mathrm{C}}\right) \times \Delta T\left({ }^{\circ} \mathrm{C}\right)
$$

where

$M$ : mass of water (density of water $\left.=1000 \mathrm{~kg} / \mathrm{m}^{3}\right)$,

Cp: specific heat of water $\left(4.184 \mathrm{~J} / \mathrm{kg}{ }^{\circ} \mathrm{C}\right)$,

$\Delta T$ : temperature difference $\left({ }^{\circ} \mathrm{C}\right)$.

The total water and energy consumption in the conventional process is $280 \mathrm{~m}^{3} /$ ton and $17,085 \mathrm{kWh} /$ ton, respectively. In the proposed process scheme, there was a saving of $83 \%$ water and $82 \%$ energy consumption. The reason for such extreme reduction is because in the proposed method, energy water and chemicals are recycled three times.

When we consider the bound water lost along with the processed fabric, it comes out to be approximately equal to the weight of the fabric, whereas the energy loss while loading and unloading the fabric and the loss to the surrounding is approximately $10 \%$ of the total energy. Thus while recycling the scouring and bleaching bath, to maintain the material to liquor ratio during the recycling processes, for 1 ton fabric, $1 \mathrm{~m}^{3}$ fresh water is to be added. Also, more chemicals need to be added for the extra $1 \mathrm{~m}^{3}$ fresh water. The energy required to heat that $1 \mathrm{~m}^{3}$ water would be $1312.8 \mathrm{kWh}(81.1+1231.9 \mathrm{kWh})$.

Table 9 Fastness properties of samples dyed with Navy Blue HER

\begin{tabular}{|c|c|c|c|c|c|c|c|}
\hline \multirow[t]{2}{*}{ Sr. no. } & \multirow{2}{*}{$\begin{array}{l}\text { Dyed fabric } \\
\text { samples }\end{array}$} & \multicolumn{3}{|c|}{ Washing fastness } & \multicolumn{2}{|c|}{ Rubbing fastness } & \multirow{2}{*}{$\begin{array}{l}\text { Light } \\
\text { fastness }\end{array}$} \\
\hline & & $\overline{C C}$ & SC & SW & Dry & Wet & \\
\hline 1. & STD RFD sample & $4-5$ & $3-4$ & 4 & $4-5$ & 4 & $5-6$ \\
\hline 2. & S:B 50:50 & $4-5$ & $3-4$ & 4 & $4-5$ & 4 & $5-6$ \\
\hline 3. & $S: B$ 70:30 & $4-5$ & $3-4$ & 4 & $4-5$ & 4 & $5-6$ \\
\hline 4. & S:B 30:70 & $4-5$ & $3-4$ & 4 & $4-5$ & 4 & $5-6$ \\
\hline
\end{tabular}

CC change in colour, SC staining on cotton, SW staining on wool
Table 10 Water and energy consumption for conventional processes

\begin{tabular}{llll}
\hline $\begin{array}{l}\text { Steps in the conventional } \\
\text { processes }\end{array}$ & $\begin{array}{l}\text { Water } \\
\text { consumption } \\
\left(\mathrm{m}^{3} / \text { ton) }\right.\end{array}$ & $\begin{array}{l}\text { Energy } \\
\text { consumption } \\
\text { (kWh/ton) }\end{array}$ & $\begin{array}{l}\text { Cost } \\
\text { (Rs/ton) }\end{array}$ \\
\hline Desizing (MLR 1:20) & 20 & 697 & 5578 \\
Hot wash (MLR 1:50) & 50 & 4068 & 32,542 \\
Scouring (MLR 1:30) & 30 & 2441 & 19,525 \\
Hot wash (MLR 1:50) & 50 & 4068 & 32,542 \\
Bleaching (MLR 1:30) & 30 & 1743 & 13,946 \\
Hot wash (MLR 1:50) & 50 & 4068 & 32,542 \\
Neutralisation (MLR 1:50) & 50 & 0 & 0 \\
Total & 280 & 17,085 & 136,677
\end{tabular}

$\mathrm{a}_{1} \mathrm{kWh}=8 \mathrm{INR}$

\section{Conclusions}

The proposed sustainable pre-treatment process was highly efficient in conserving water, energy and process chemicals. When the scouring and bleaching process baths were recycled, $36 \%$ excess utilisation of alkali in the scouring process was observed when compared with the conventional process whereas in bleaching, $30 \%$ excess usage of alkali and $25.6 \%$ of that of hydrogen peroxide was seen. The fabric properties after recycling remained unchanged. When the scouring and bleaching process water containing unexhausted alkali and hydrogen peroxide was reused to desize a new grey fabric, there was a 10fold increase in absorbency and 2.7 times increase in whiteness index. Considering the economical perspective, for processing 1 ton fabric/day, there was a saving of $83 \%$ water, $74 \%$ energy and 101542 INR. By properly understanding the potential of waste stream, we can generate new resources of water and chemicals. This will reduce the intake of fresh water and minimise the load on the effluent treatment plant.

Table 11 Water and energy consumption for the proposed recycle and reuse method

\begin{tabular}{llll}
\hline $\begin{array}{l}\text { Steps in the proposed } \\
\text { recycle and reuse } \\
\text { process }\end{array}$ & $\begin{array}{l}\text { Water } \\
\text { consumption } \\
\text { (m³/ton) }\end{array}$ & $\begin{array}{l}\text { Energy } \\
\text { consumption } \\
\text { (kW/ton) }\end{array}$ & $\begin{array}{l}\text { Cost } \\
\text { (Rs/ton) }\end{array}$ \\
\hline $\begin{array}{l}\text { Desizing (MLR 1:20) } \\
\text { Hot wash (MLR 1:50) }\end{array}$ & 0 & 0 & 0 \\
Scouring (MLR 1:30) & 7.5 & 0 & 0 \\
Hot wash (MLR 1:50) & 12.5 & 610 & 4881 \\
Bleaching (MLR 1:30) & 7.5 & 1017 & 8135 \\
Hot wash (MLR 1:50) & 12.5 & 436 & 3486 \\
Neutralisation (MLR 1:50) & 12.5 & 1017 & 8135 \\
Total & 52.5 & 0 & 0 \\
\hline
\end{tabular}




\section{Competing interests}

The authors declare that they have no competing interests.

\section{Authors' contributions}

$\mathrm{RH}$ carried out all the experimental work stated here and have drafted the manuscript. RA has provided guidance for carrying out the experiments and has helped in reviewing the manuscript. Both authors read and approved the final manuscript.

\section{Authors' information}

Rachana S. Harane is currently pursuing her Ph.D. from the Department of Fibres and Textile Processing Technology, ICT, Mumbai, and her research interest lies in reuse and recycling of wastewater, textile pre-treatment and dyeing, textile effluent treatment and water conservation in textile wet processing.

Ravindra V. Adivarekar is Ph.D. (Tech) from ICT (formerly known as UDCT), Mumbai. He is, at present, a Professor of Fibre Chemistry and Head of the department at ICT. His research interests include printing of textile, natural dyes, mass production and extraction of microbial colourants, manufacturing of enzymes for textile processing, medical textile, textile composites, eco-friendly processing, water conservation in textiles and detergency of textiles.

\section{Acknowledgements}

We acknowledge the University Grants Commission- Special Assistance Programme (UGC-SAP) for scholarship and DST-FIST programme of Indian government for providing the testing facilities.

\section{Received: 23 December 2015 Accepted: 24 February 2016}

\section{Published online: 11 March 2016}

\section{References}

A technical report on, Water Use in Indian Industry Survey (2011). FICCI Water Mission. New Delhi.

American Public Health Association, American Water Works Association, Water Environment Federation (1999). Standard Methods for the Examination of Water and Wastewater. 541.

Chehna, AB, Agrawal, N, Ricard, LB, Smith, GM, Varley, AR (2007). AATCC Technical Manual, 82, North Carolina.

Dasgupta, J., Sikder, J., Chakraborty, S., et al. (2015). Remediation of textile effluents by membrane based treatment techniques: a state of the art review. Journal of Environmental Management, 147, 55-72. doi:10.1016/j.jenvman.2014.08.008

ElDefrawy, N. M. H., \& Shaalan, H. F. (2007). Integrated membrane solutions for green textile industries. Desalination, 204, 241-254. doi:10.1016/j.desal. 2006.03.542.

Erdumlu, N., Ozipek, B., Yilmaz, G., \& Topatan, Z. (2012). Reuse of effluent water obtained in different textile finishing processes. Autex Res J, 12, 23-28. doi:10.2478/v10304-012-0005-9.

Fersi, C., Gzara, L., \& Dhahbi, M. (2005). Treatment of textile effluents by membrane technologies. Desalination, 185, 399-409. doi:10.1016/j.desal.2005.03.087.

Koushik, C. V., \& Josico, A. I. (2003). Chemical processing of textiles: Preparatory processes and dyeing. New Delhi: NCUTE.

Lu, X., Liu, L., Liu, R., \& Chen, J. (2010). Textile wastewater reuse as an alternative water source for dyeing and finishing processes: a case study. Desalination, 258, 229-232. doi:10.1016/j.desal.2010.04.002.

Cardamone \& Marmer (1995). The whitening of textiles. In CM Carr (Ed.), Chemistry of textile industry (pp. 53). Glasgow: Blackie Academic and Professional.

Rahman Bhuiyan, M. A., Mizanur Rahman, M., Shaid, A., Bashar, M. M., \& Khan, M. A. (2016). Scope of reusing and recycling the textile wastewater after treatment with gamma radiation. Journal of Cleaner Production, 112(4), 3063-3071.

Ranganathan, K., Karunagaran, K., \& Sharma, D. C. (2007). Recycling of wastewaters of textile dyeing industries using advanced treatment technology and cost analysis-case studies. Resources, Conservation and Recycling, 50, 306-318. doi:10.1016/j.resconrec.2006.06.004.

Schoeberl, P., Brik, M., Braun, R., \& Fuchs, W. (2005). Treatment and recycling of textile wastewater-case study and development of a recycling concept. Desalination, 171, 173-183. doi:10.1016/j.desal.2004.02.105.

Shaid, A., Osman, S., Hannan, A., \& Bhuiyan, M. A. R. (2013). Direct reusing of textile wastewater in scouring-bleaching of cotton goods devoid of any treatment. International Journal of Engineering Research and Development, 5, 45-54.

Shore, J. (1995). Cellulosics Dyeing. England: Society of Dyers and Colorists.

Skelly, J. K. (2003). Reuse of water form scouring and bleaching processes. In J. K. Skelly (Ed.), Water recycling in textile wet processing. England: Society of Dyers and Colourists.

Sule, A. D. (1997). Computer colour analysis: textile applications. New Delhi: New Age International Publishers.

Tests for Colour Fastness - Part B02: Colour fastness to artificial light: xenon arc fading lamp test (2013). ISO 105 B02, Interational Organisation for Standardisation. Geneva: ISO.

Tests for Colour Fastness - Part C03: Colour fastness to washing (1989). ISO 105 C03, Interational Organisation for Standardisation. Geneva: ISO.

Tests for Colour Fastness - Part X12: Colour fastness to rubbing (2001). 150105 X12, Interational Organisation for Standardisation. Geneva: ISO.

Tomasino, C. (1992). Chemistry \& Technology of Fabric Preparation \& Finishing. Raleigh: Department of Textile Engineering, Chemistry and Science, College of Textiles, North Carolina State University.

U S Environmental Protection Agency. (2004). Guidelines for water reuse. Development, 26, 252

Wurster, P., et al. (1987). The TEGEWA drop test, a method for the rapid determination of textile fabric absorption. Melliand Textilberichte, 68, 581-583.

\section{Submit your manuscript to a SpringerOpen ${ }^{\circ}$ journal and benefit from:}

- Convenient online submission

- Rigorous peer review

- Immediate publication on acceptance

- Open access: articles freely available online

- High visibility within the field

- Retaining the copyright to your article

Submit your next manuscript at $>$ springeropen.com 